Hetty Karunia Tunjungsari, Frangky Selamat, Chairy: Pengukuran Destination Awareness Wisatawan Domestik pada Candi Muaro Jambi

\title{
Pengukuran Destination Awareness Wisatawan Domestik pada Candi Muaro Jambi
}

\author{
Hetty Karunia Tunjungsari, Frangky Selamat, Chairy \\ Fakultas Ekonomi dan Bisnis, Universitas Tarumanagara, Jl. Tanjung Duren Utara No. 1 Grogol, \\ Jakarta Barat dan Fakultas Bisnis, Universitas Presiden, Jababeka Education Park, Jl. Ki Hajar \\ Dewantara, Kec. Cikarang Utara, Bekasi, \\ hetty@fe.untar.ac.id,frangkys@fe.untar.ac.id, chairy@president.ac.id
}

Masuk tanggal: 27-10-2019, revisi tanggal: 25-11-2019, diterima untuk diterbitkan tanggal : 25-11-2019

\begin{abstract}
This research focuses on measuring the destination awareness of domestic tourists in a number of tourist destinations in Indonesia. Questionnaire-based survey was conducted by researchers to find out how domestic tourists' destination awareness of tourist destinations: Borobudur, Monas, Ulundanu Temple, Tana Toraja, and Muaro Jambi Temple. The main purpose of this destination awareness measurement is to confirm presupposition that in general there are still very limited domestic tourists who are aware of Muaro Jambi Temple as one of tourist's destination in Indonesia. Research hypothesis is proposed with the allegation that there are differences in the destination awareness of domestic tourists towards the tourist destinations of Borobudur, Monas, Ulundanu Temple, Tana Toraja, and Muaro Jambi Temples. Muaro Jambi Temple is suspected to have the lowest level of awareness compared to other tourist destinations. The hypothesis in this study is supported by data, the level of awareness of domestic tourists over Muaro Jambi Temple is lower than the level of awareness of the Borobudur, Monas, Ulundanu Temples, and Tana Toraja. Theoretically the results of this study bring scientific contributions related to the field of destination marketing, specifically related to the destination awareness of a domestic tourist destination. Practically, the results of this study can become the basis for establishing destination marketing policies aimed at increasing domestic tourist awareness of various tourist destination in Indonesia.
\end{abstract}

Keywords: Destination awareness, tourist destination, domestic tourist, tourist's preferences

\begin{abstract}
Abstrak
Penelitian ini berfokus pada pengukuran destination awareness wisatawan domestik sejumlah destinasi wisata di Indonesia. Survei berbasis kuesioner dilakukan oleh peneliti untuk mengetahui bagaimana destination awareness wisatawan domestik terhadap destinasi wisata Candi Borobudur, Monas, Pura Ulundanu, Tana Toraja, dan Candi Muaro Jambi. Tujuan utama pengukuran destination awareness ini adalah untuk mendapatkan dukungan terhadap dugaan peneliti bahwa secara umum wisatawan domestik yang mengenal Candi Muaro Jambi sebagai pilihan destinasi wisata di Indonesia masih sangat terbatas. Hipotesis dalam penelitian ini diajukan dengan dugaan bahwa terdapat perbedaan destination awareness wisatawan domestik terhadap destinasi wisata Candi Borobudur, Monas, Pura Ulundanu, Tana Toraja, dan Candi Muaro Jambi. Candi Muaro Jambi diduga memiliki tingkat awareness yang paling rendah dibandingkan dengan destinasi wisata lain yang diteliti. Hipotesis dalam penelitian ini didukung oleh
\end{abstract}


data, tingkat awareness wisatawan domestik atas Candi Muaro Jambi lebih rendah dibandingkan dengan tingkat awareness atas Candi Borobudur, Monas, Pura Ulundanu, dan Tana Toraja. Secara teoretis, hasil penelitian ini memberikan kontribusi ilmiah terkait dengan bidang pemasaran destinasi, khususnya terkait dengan destination awareness suatu destinasi wisata domestik. Secara praktis, hasil penelitian ini dapat menjadi dasar pembentukan kebijakan pemasaran destinasi yang bertujuan untuk meningkatkan awareness wisatawan domestik terhadap berbagai destinasi wisata yang ada di Indonesia.

Kata Kunci: destination awareness, destinasi wisata, wisatawan domestik, preferensi wisatawan

\section{Pendahuluan}

Travel and Tourism Competitiveness Index (TTCI) World Economic Forum (WEF) menempatkan Indonesia di peringkat 42 pada tahun 2017 dan pemerintah Indonesia menargetkan peningkatan peringkat di posisi ke-30 dunia di tahun 2019. Di Indonesia, dikeenal cukup banyak destinasi wisata yang ramai dikunjungi baik oleh wisatawan domestik maupun mancanegara. Sebut saja pantai Kuta-Bali, Monas-Jakarta, candi Borobudur-Yogyakarta, danau Toba-Medan, hingga Raja Ampat-Papua. Jenis destinasi wisata tersebut bervariasi mulai dari destinasi wisata alam, destinasi wisata sejarah, hingga destinasi wisata budaya. Di tahun 2005, United Nations World Tourism Organization (UNWTO) melaporkan bahwa kunjungan ke destinasi wisata warisan budaya dan sejarah telah menjadi salah satu kegiatan wisata yang tercepat pertumbuhannya (Timothy dan Nyaupane, 2009). Dua jenis kegiatan wisata yang erat hubungannya dengan warisan budaya dan peninggalan sejarah adalah cultural tourism (wisata budaya) dan heritage tourism (wisata ke situs-situs warisan atau pusaka). Indonesia kaya akan warisan budaya dan sejarah, mulai dari Candi Borobudur, Candi Prambanan, Candi Mendut, Candi Sukuh, Candi Cetho, Candi Plaosan, Candi Muaro Jambi, dan masih banyak candi-candi lain yang tersebar di pulau Jawa, Sumatera, Kalimantan yang merupakan peninggalan bersejarah Hindu-Budha.

Wang dan Pizam (2011) menyatakan bahwa pemasaran dan manajemen destinasi dapat didefinisikan sebagai pendekatan proaktif, berpusat pada pengunjung untuk pengembangan ekonomi dan budaya dari destinasi yang menyeimbangkan dan mengintegrasikan kepentingan pengunjung, penyedia layanan dan masyarakat. Definisi ini menunjukkan bahwa pemasaran dan manajemen destinasi adalah masalah kompleks yang memerlukan pendekatan holistik dan sistematis yang harus mencakup penelitian. Dalam beberapa tahun terakhir semakin banyak peneliti dan profesional pemasaran menggunakan konsep inovatif untuk destinasi dan merek destinasi. Govers and Go (2009) percaya bahwa "place branding" mengacu pada "membangun ekuitas merek dalam kaitannya dengan negara, kawasan, dan / atau identitas lokal (atau kota)".

Di mata wisatawan, kemenarikan suatu destinasi wisata menjadi salah satu kunci pendorong minat wisawatan untuk berkunjung ke lokasi tersebut. Tidak jarang wisawatan rela berkunjung berulang kali ke suatu destinasi wisata karena merasa puas setelah menikmati kunjungan wisatanya. Namun demikian, perlu diperhatikan pula bahwa wisatawan tentu memiliki keinginan untuk berkunjung 
Hetty Karunia Tunjungsari, Frangky Selamat, Chairy: Pengukuran Destination Awareness Wisatawan Domestik pada Candi Muaro Jambi

ke destinasi-destinasi wisata lain yang belum pernah dikunjunginya. Mereka akan mencari informasi seputar destinasi wisata yang belum pernah dikunjungi dari berbagai sumber, baik dari keluarga, rekan, media informasi, hingga media sosial. Oleh sebab itu, penting bagi pengelola destinasi wisata saat ini untuk terus mempublikasikan dirinya agar wisatawan-wisatawan baru dapat mengetahui informasi positif terkait destinasi tersebut dan kemudian tertarik untuk berkunjung.

Berdasarkan sasaran pembangunan pariwisata yang disusun oleh Kementerian Pariwisata untuk tahun 2015-2019 sebagaimana ditampilkan Tabel 1 dapat dilihat bahwa di tahun 2019 kunjungan wisatawan nusantara ditargetkan berjumlah 275 juta, lebih dari 10 kali lipat target kunjungan wisatawan mancanegara. Dengan demikian, perlu dipahami bersama baik oleh pemerintah maupun pengelola destinasi wisata, bahwa promosi destinasi wisata yang ditujukan pada wisatawan domestik perlu lebih diperhatikan dan ditingkatkan. Strategi promosi yang tepat dapat disusun jika pengelola destinasi wisata dapat memahami dengan baik faktor-faktor apa saja yang dapat ditawarkan bagi para wisatawan yang akan berkunjung. Selain itu, pemahaman mengenai tingkatan brand awareness wisatawan terhadap suatu destinasi wisata juga sangat diperlukan.

Tabel 1. Sasaran Pembangunan Pariwisata

\begin{tabular}{|c|l|c|c|}
\hline \multicolumn{2}{|c|}{ Uraian Sasaran } & Baseline 2014 *) & $\mathbf{2 0 1 9}$ \\
\hline 1. & Kontribusi terhadap PDB Nasional & $4,0 \%$ & $9,2 \%$ \\
\hline 2. & Wisatawan Mancanegara (Orang) & 9,3 juta & 20,0 juta \\
\hline 3. & Wisatawan Nusantara (Kunjungan) & 251 juta & 275 juta \\
\hline 4. & Devisa (Milliar USD) & 10,69 & 20 \\
\hline
\end{tabular}

Sumber: Kementerian Parekraf. Buku I RPJMN 2015-2019.

Saat ini banyak pengelola destinasi wisata lebih berfokus untuk mempromosikan destinasi wisata kepada wisatawan mancanegara. Melalui survei pendahuluan yang telah dilakukan oleh peneliti pada 30 wisatawan domestik yang gemar melakukan perjalanan wisata ke berbagai daerah di Indonesia tidak ditemukan Candi Muaro Jambi sebagai salah satu destinasi wisata yang pernah mereka kunjungi. Bahkan tidak satupun responden menyebutkan kota Jambi sebagai salah satu kota yang ingin mereka kunjungi di masa mendatang. Kondisi ini menunjukkan rendahnya tingkat brand awareness wisatawan terhadap Candi Muaro Jambi. Hal ini tentu sangat memprihatinkan mengingat sejak tahun 2009 Kompleks Candi Muaro Jambi telah dicalonkan ke UNESCO untuk menjadi Situs Warisan Dunia.

Penelitian ini bertujuan untuk mengukur brand awareness wisatawan domestik di sejumlah destinasi wisata di Indonesia sebagai bagian dari penelitian yang didanai oleh Kemenristekdikti tahun 2019. Survei berbasis kuesioner akan 
dilakukan oleh peneliti untuk mengetahui bagaimana brand awareness wisatawan domestik terhadap destinasi wisata Candi Borobudur, Monas, Pura Ulundanu, Tana Toraja, dan Candi Muaro Jambi. Tujuan utama pengukuran brand awareness ini adalah untuk mendapatkan dukungan terhadap dugaan peneliti bahwa secara umum wisatawan domestik yang mengenal Candi Muaro Jambi sebagai pilihan destinasi wisata yang dapat dikunjungi masih sangat terbatas

Salah satu ukuran untuk melihat bagaimana wisatawan telah mengenal suatu destinasi adalah dengan mengadopsi konsep brand awareness yang dikenal di bidang pemasaran produk/jasa sebagai destination awareness. Seperti halnya dengan tingkatan brand awareness, destination awareness suatu destinasi wisata mengindikasikan seberapa jauh wisatawan mengenal destinasi wisata tersebut. Pengelola destinasi wisata perlu memahami dengan baik tingkatan destination awareness yang dimilikinya agar dapat mengetahui strategi promosi yang tepat untuk menarik wisatawan. Banyak wisatawan tidak mengetahui adanya suatu destinasi wisata karena promosi yang dilakukan oleh pengelola destinasi tidak mampu menjangkau mereka. Sebagai akibatnya, destinasi wisata tersebut tidak dapat memaksimalkan kunjungan wisatawan.

\section{Branding dalam Destinasi Wisata}

Negara, kota, dan tujuan, dalam perspektif umum, menghadapi tantangan penting baru di masa ini. Mereka setiap hari dituntut untuk mencari keunggulan kompetitif mereka dan terus meningkatkan citra di mata masyarakat global maupun wisatawan secara khusus. Oleh sebab itu, mereka perlu menerapkan konsep branding dan manajemen merek agar dapat meraih kunci kesuksesan dalam membentuk citra positif dan kuat. Suatu destinasi yang kompetitif adalah mereka yang berhasil menciptakan pengetahuan dan memfasilitasi pembelajaran, secara terbuka menonjolkan perbedaan mereka dan kompetensi khas mereka di mata pengunjung (Cidrais, 2006).

Jika dikaitkan dengan destinasi, destination branding adalah sekelompok aktivitas pemasaran yang mendukung penciptaan nama, simbol, logo, tanda katakata atau grafis lain yang siap mengidentifikasi dan membedakan sebuah destinasi yang secara konsisten menyampaikan harapan sebuah perjalanan yang mudah diingat; melayani untuk konsolidasi dan memperkuat hubungan emosional antara pengunjung dan destinasi; dan mengurangi biaya pencarian konsumen dan risiko yang dipersepsikan. Secara kolektif, aktivitas ini melayani untuk menciptakan citra destinasi yang secara positif mempengaruhi pilihan destinasi konsumen (Blain, Levy \& Ritchie, 2005).

Menurut Braun dan Zenker (2010) dan Saraniemi dan Kylanen (2011) merek suatu destinasi atau tujuan adalah jaringan lembaga dan aktor yang berlokasi di tempat fisik atau virtual di mana transaksi dan kegiatan terkait pemasaran terjadi, yang dibangun dalam pikiran konsumen dari ekspresi visual, verbal dan perilaku suatu tempat. Komunikasi, nilai-nilai dan budaya membangun merek destinasi berdasarkan persepsi konsumen terhadap elemen-elemen tersebut (Kavaratzis \& Ashworth, 2006). Branding dalam destinasi mencoba menciptakan asosiasi emosional, kognitif dan psikologis dengan tujuan, menjadi titik awal yang baik untuk komunikasi terpadu dan pendekatan pemasaran dari masing-masing 
Hetty Karunia Tunjungsari, Frangky Selamat, Chairy: Pengukuran Destination Awareness Wisatawan Domestik pada Candi Muaro Jambi

tujuan (Kavaratzis \& Ashworth, 2006; Rainisto, 2003). Namun, sebelum sebuah destinasi memiliki merek serta dapat menentukan posisi atas mereknya, destinasi tersebut harus mendefinisikan identitasnya, atributnya dan area pengembangannya (Rainisto, 2003). Williams, Gill, dan Chura (2004) mengemukakan bahwa merek sebuah destinasi dirancang untuk menciptakan identitas unik dan menarik yang menyampaikan nilai-nilai baik secara sadar atau intuitif terkait dengan 'selera' suatu destinasi.

\section{Citra Destinasi}

Citra merupakan kesan keseluruhan dengan beberapa kondisi emosional (Oxenfeldt, 1974). Dobni dan Zinkhan (1990) menyimpulkan bahwa citra adalah fenomena persepsi yang terbentuk melalui interpretasi emosional konsumen dengan komponen kognitif dan afektif. Definisi citra destinasi berhubungan dengan persepsi individu atau kelompok dari suatu destinasi (Crompton, 1979; Jenkins, 1999; Min, Martin, \& Jung, 2013; Zeugner-Roth \& Žabkar, 2015). Citra destinasi adalah sistem pemikiran, pendapat, perasaan, visualisasi, dan intensi-tasi yang interaktif terhadap suatu tujuan (Költringer \& Dickinger, 2015; Tasci \& Gartner, 2007). Keseluruhan atau gabungan hasil dari interaksi antara sikap pilihan konsumen ini (Gartner, 1989; Lin, Morais, Kerstetter, \& Hou, 2007; Pike \& Ryan, 2004). Karakteristik produk atau layanan pariwisata, seperti multidimensionalitas (Gartner, 1989; Zeugner-Roth \& Žabkar, 2015) dan intangibilitas (Fakeye \& Crompton, 1991), memperumit pengukuran konstruk citra destinasi.

Citra destinasi merupakan dimensi dari identitas merek suatu destinasi. Menurut Tsaur, Yen \& Yan (2016), identitas merek terbagi atas lima dimensi yaitu destination image, destination awareness, destination quality, destination personality dan destination culture. Berikut ini adalah penjelasan mengenai masing-masing dimensi dari identitas merek destinasi wisata:

a. Destination image. Gartner (1989) mendeskripsikan destination image atau citra destinasi sebagai sebuah fungsi dari merek, yaitu persepsi wisatawan dan penjual dari aktivitas atau atraksi yang tersedia di area destinasi.

b. Destination awareness. Menurut Tsaur, Yen \& Yan (2016), brand awareness direfleksikan oleh kemampuan konsumen untuk mengidentifikasi merek di bawah kondisi yang berbeda. Selanjutnya, destination awareness merujuk pada pengetahuan yang dimiliki wisatawan atas produk destinasi. Milman \& Pizam (1995) mengemukakan bahwa agar awareness dari wisatawan tercapai, harus diikuti dengan citra yang positif. Awareness juga mewakili kekuatan akan kehadiran merek di dalam pikiran konsumen (Aaker, 1996). Oleh karenanya destination awareness menjadi hal yang esensial di dalam identitas merek.

c. Destination quality. Destination quality merujuk pada persepsi wisatawan mengenai kemampuan destinasi untuk memenuhi ekspektasinya (Ferns \& Walls, 2012).

d. Destination personality. Destination personality merujuk pada karakteristik manusia yang diasosiasikan dengan merek (Aaker, 1996). 
e. Destination culture. Destination culture merujuk pada dimensi budaya atau kode sebuah merek seperti sejarah, citra, mitos, seni dan teater yang mempengaruhi arti merek di dalam pasar (Schroeder, 2005).

Hubungan antara citra destinasi dan niat perilaku tetap menjadi masalah yang dapat diperdebatkan. Citra yang baik dapat mempengaruhi patronase ulang (Dick \& Basu, 1994). Sejumlah penelitian mengenai citra hotel mengakui bahwa citra destinasi mempengaruhi perilaku wisatawan dan pilihan destinasi (Baloglu \& McCleary, 1999; Költringer \& Dickinger, 2015; Milman \& Pizam, 1995; Woodside \& Lysonski, 1989). Citra destinasi mempengaruhi wisatawan dalam proses memilih destinasi dan mengunjungi kembali destinasi di masa depan (Hosany \& Prayag, 2013; Zeugner-Roth \& Žabkar, 2015).

\section{Hipotesis Penelitian}

Berdasarkan pemaparan pada bagian di atas, penelitian ini bertujuan untuk mengetahui seberapa jauh wisatawan nusantara mengenal Candi Muaro Jambi sebagai sebuah brand destinasi wisata dengan mengukur destination awareness Candi Muaro Jambi dibandingkan dengan sejumlah destinasi wisata terkemuka di Indonesia. Destinasi wisata yang diukur destination awareness-nya dalam penelitian ini ditentukan melalui sebuah studi pendahuluan yang melibatkan 30 responden. Responden diminta untuk menuliskan 5 destinasi wisata terkemuka di Indonesia yang mereka ketahui. Mereka juga diminta untuk menuliskan 5 kota tujuan wisata yang paling terkenal di Indonesia.

Hipotesis yang diajukan dalam penelitian ini adalah sebagai berikut:

"Candi Muaro Jambi memiliki tingkat destination awareness yang lebih rendah dibandingkan dengan (a) Candi Borobudur, (b) Monas, (c) Pura Ulundanu, dan (d) Tana Toraja."

\section{Metode Penelitian}

Populasi dalam penelitian ini adalah wisatawan nusantara yang tersebar di berbagai wilayah di Indonesia. Metode pengambilan sampel dalam penelitian ini adalah purposive sampling, dimana peneliti melakukan pengambilan sampel secara non acak dengan menetapkan ciri-ciri khusus sesuai dengan tujuan penelitian. Adapun sampel penelitian adalah wisatawan yang berasal dari mahasiswa, dosen, wirausaha, pegawai swasta, dan ibu rumah tangga yang berada di berbagai wilayah di Indonesia.

Data dalam penelitian ini diperoleh melalui penyebaran survei secara online melalui email, Whatsapp, dan Instagram. Selain itu, survei juga disebarkan secara manual kepada para wisatawan yang berkunjung ke Candi Muaro Jambi. Survei online dilakukan pada bulan April hingga September 2019. Adapun penyebaran kuesioner secara manual di Candi Muaro Jambi dilakukan pada bulan Juli 2019.

Instrumen penelitian berupa kuesioner diadaptasi dari Rositter (2014) dimana untuk mengetahui tingkatan destination awareness (brand awareness atas destinasi) responden diminta untuk menjawab sejumlah pertanyaan seperti: 
Hetty Karunia Tunjungsari, Frangky Selamat, Chairy: Pengukuran Destination Awareness Wisatawan Domestik pada Candi Muaro Jambi

Pernahkah Anda melihat destinasi wisata berikut ini sebelumnya (Ya/Tidak) destination recognition; Saat Anda berpikir untuk mengunjungi suatu destinasi wisata, destinasi wisata manakah yang pertama kali muncul di pikiran Anda? (jawaban dalam bentuk urutan peringkat dari paling cepat muncul hingga paling akhir muncul di pikiran responden) - destination recall; Sebutkan 5 kota tujuan wisata terkenal di Indonesia (jawaban dalam bentuk urutan peringkat dari paling terkenal hingga yang kurang terkenal) - top of mind.

Untuk mengukur destination awareness atas destinasi wisata dalam penelitian ini, yakni Candi Borobudur, Monas, Tana Toraja, Pura Ulundanu dan Candi Muaro Jambi, responden diminta untuk menyebutkan urutan destinasi wisata yang paling dikenal hingga yang kurang dikenal. Gambar 1 berikut ini digunakan untuk mengukur destination awareness dari masing-masing destinasi wisata yang diteliti.

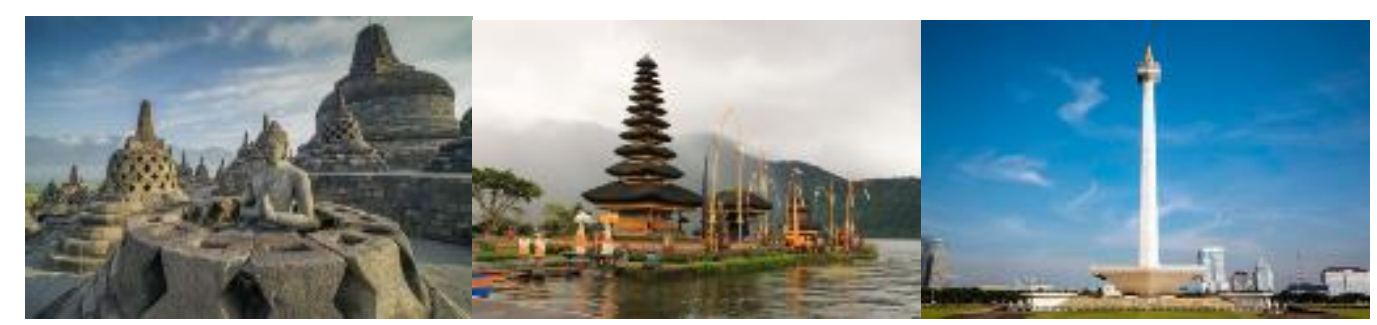

Candi Borobudur

Pura Ulun Danu

Monas

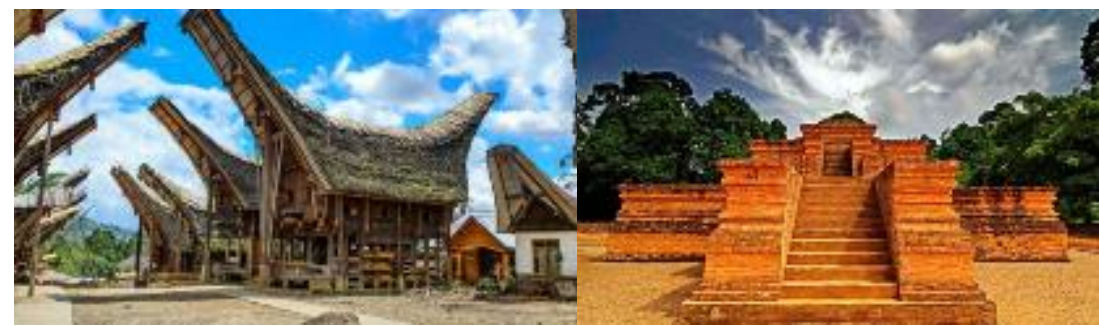

Tana Toraja

Candi Muaro Jambi

Gambar 1. Foto Destinasi Wisata

Sumber: https://google.com

Untuk mengukur tingkat minat mengunjungi Candi Muaro Jambi, peneliti meminta responden untuk mengakses video liputan Candi Muaro Jambi dengan mengklik link yang tersedia di laman kuesioner. Video liputan diperoleh dari sumber Youtube dengan link https://www.youtube.com/watch?v=Ahn_4nZ0cv0. Setelah menyaksikan video tersebut kemudian responden diminta untuk memberikan penilaian terkait dengan minat untuk mengunjungi Candi Muaro Jambi, mulai dari Sangat Tidak Berminat, Tidak Berminat, Kurang Berminat, Cukup Berminat, Berminat, hingga Sangat Berminat. 


\section{Hasil Penemuan dan Diskusi}

Penelitian ini melibatkan responden dari berbagai kalangan usia, latar belakang pendidikan, latar belakang profesi dan domisili yang tersebar di berbagai daerah di Indonesia. Survey yang dilakukan melalui pengiriman link google form secara online di berbagai media sosial dan email yang berada di jejaring peneliti sejak bulan April hingga September 2019 telah diikuti oleh 357 responden. Terdapat sebanyak 46,8\% responden wanita dan $53.2 \%$ responden pria yang berasal dari berbagai kota di Indonesia. Responden memiliki latar belakang pendidikan SMA sebanyak 15,7\%, S1 sebanyak 41,5\%, S2 sebanyak 36,7\% dan sisanya sebanyak $6,1 \%$ berlatar belakang S3. Mayoritas responden adalah pegawai swasta $(33,9 \%)$, diikuti oleh pelajar $(19,6 \%)$, lainnya $(17,9 \%)$ dan PNS $(17,6 \%)$. Responden yang telah menikah sebanyak $57,7 \%$ dan mayoritas usia responden berada pada kisaran 20-30 tahun (38,9\%).

Terdapat sebanyak 37 responden atau 10,4\% wisawatan yang pernah berkunjung ke Candi Muaro Jambi. Dari ke-37 responden tersebut, mayoritas berkunjung untuk mempelajari peninggalan bersejarah $(48,6 \%)$, menikmati suasana rileks $(24,3 \%)$, beribadah $(18,9 \%)$ dan bersepeda mengelilingi lokasi candi $(0,8 \%)$. Pengukuran atas kepuasan wisatawan yang berkunjung ke Candi Muaro Jambi menunjukkan bahwa mayoritas wisawatan menyatakan cukup puas mengunjungi Candi Muaro Jambi. Terdapat sebanyak 18,1\% wisawatan menyatakan Puas, 20,5\% Cukup Puas, 24,3\% Kurang Puas dan 16,2\% Tidak Puas.

Pada pertanyaan $5 \mathrm{kota} /$ destinasi wisata paling terkenal di Indonesia, diperoleh peringkat jawaban responden dari yang terbanyak hingga terendah sebagai berikut: Bali, Yogyakarta, Raja Ampat, Jakarta, Pulau Komodo, Lombok, Medan, Labuan Bajo. Pada Tabel 2 dapat dilihat peringkat dan frekuensi jawaban responden terkait pertanyaan ini. Dari jawaban responden tersebut dapat disimpulkan bahwa belum terdapat destination recognition responden atas kota Jambi.

\begin{tabular}{lcc}
\multicolumn{3}{c}{ Tabel 2. Kota/Destinasi Wisata Terkenal di Indonesia } \\
\hline \multicolumn{1}{c}{ Kota } & Jumlah Jawaban & $\begin{array}{c}\text { Persentase } \\
\text { Jawaban }\end{array}$ \\
\hline Bali & 243 & 68,1 \\
Yogyakarta & 55 & 15,4 \\
Raja Ampat & 26 & 7,3 \\
Jakarta & 16 & 4,5 \\
Pulau Komodo & 13 & 3,6 \\
Lombok & 2 & 0,6 \\
Medan & 1 & 0,3 \\
Labuan Bajo & 1 & 0,3 \\
\hline Total & 357 & 100 \\
\hline
\end{tabular}

Hasil jawaban responden atas pengukuran destination awareness dari Candi Borobudur, Pura Ulundanu, Monas, Tana Toraja, dan Candi Muaro Jambi menunjukkan bagaimana mereka mengenal masing-masing destinasi wisata ini. 
Hetty Karunia Tunjungsari, Frangky Selamat, Chairy: Pengukuran Destination Awareness Wisatawan Domestik pada Candi Muaro Jambi

Tabel 3 menunjukkan frekuensi jawaban responden untuk masing-masing destinasi wisata. Dari tabel ini, dapat dilihat bahwa seluruh responden mengenal Monas dan Candi Muaro Jambi memiliki tingkat awareness yang paling rendah dibandingkan dengan keempat destinasi lainnya.

Tabel 3. Destination awareness Responden

\begin{tabular}{lcc}
\hline Destinasi & $\begin{array}{c}\text { Frekuensi } \\
\text { Jawaban "YA" }\end{array}$ & $\begin{array}{c}\text { Persentasi } \\
\text { Jawaban "YA" }\end{array}$ \\
\hline Monas & 357 & 100 \\
Candi Borobudur & 356 & 99,7 \\
Pura Ulun Danu & 240 & 67,2 \\
Tana Toraja & 215 & 60,2 \\
Candi Muaro Jambi & 62 & 17,1 \\
\hline
\end{tabular}

Untuk menguji hipotesis dalam penelitian ini peneliti menggunakan statistik paired samples test. Dari Tabel 4 dan 5 dapat disimpulkan bahwa awareness responden pada Candi Muaro Jambi dibandingkan dengan Candi Borobudur, Pura Ulundanu, Monas, dan Tana Toraja secara keseluruhan memiliki perbedaan yang signifikan dan nilai mean untuk Candi Muaro Jambi secara signifikan lebih rendah dibandingkan dengan nilai mean Candi Borobudur, Pura Ulundanu, Monas, dan Tana Toraja. Hasil pengujian paired samples test ini mendukung hipotesis 2, diperoleh hasil Candi Muaro Jambi memiliki nilai mean destination awareness yang lebih rendah dibandingkan dengan nilai mean awareness (a) Candi Borobudur, (b) Monas, (c) Pura Ulundanu, dan (d) Tana Toraja.

Tabel 4. Statistik Pair Samples

\begin{tabular}{ll|r|r|r|r}
\hline & & Mean & $\mathrm{N}$ & Std. Deviation & Std. Error Mean \\
\hline Pair 1 & awareness candi borobudur & 2.00 & 357 & .053 & .003 \\
\cline { 2 - 6 } & awareness candi muaro jambi & 1.17 & 357 & .377 & .020 \\
\hline Pair 2 & awareness pura ulun danu & 1.68 & 352 & .466 & .025 \\
\cline { 2 - 6 } & awareness candi muaro jambi & 1.17 & 352 & .379 & .020 \\
\hline \multirow{2}{*}{ Pair 3 } & awareness monas & 2.00 & 357 & .000 & .000 \\
\cline { 2 - 6 } & awareness candi muaro jambi & 1.17 & 357 & .377 & .020 \\
\hline Pair 4 & awareness tana toraja & 1.60 & 357 & .490 & .026 \\
\cline { 2 - 6 } & awareness candi muaro jambi & 1.17 & 357 & .377 & .020 \\
\hline
\end{tabular}

Secara rinci perbedaan nilai mean awareness atas Candi Muaro Jambi dengan masing-masing destinasi yang dievaluasi dalam penelitian ini dapat dilihat pada Tabel 5. Sebagai contoh, secara statistik terdapat perbedaan nilai mean awareness atas Candi Muaro Jambi dengan Candi Borobudur $(\mathrm{t}=41,157 ; \mathrm{p}<0,05)$. Demikian pula halnya dengan perbedaan mean awareness Candi Muaro Jambi dan Pura Ulundanu, Monas dan Tana Toraja, seluruhnya berbeda secara signifikan dengan nilai $\mathrm{p}<0,05$. Dengan demikian, dapat disimpulkan bahwa secara statistik hipotesis 2 dalam penelitian ini didukung oleh data, Candi Muaro Jambi memiliki tingkat destination awareness yang lebih rendah dibandingkan dengan (a) Candi Borobudur, (b) Monas, (c) Pura Ulundanu, dan (d) Tana Toraja. 
Tabel 5. Hasil Pengujian Paired Samples Test

\begin{tabular}{|c|c|c|c|c|c|c|c|c|c|}
\hline & \multicolumn{5}{|c|}{ Paired Differences } & \multirow[t]{5}{*}{$\mathrm{t}$} & \multirow[t]{5}{*}{ df } & \multirow[t]{5}{*}{$\begin{array}{l}\text { Sig. (2- } \\
\text { tailed) }\end{array}$} \\
\hline & & \multirow[b]{4}{*}{ Mean } & \multirow{4}{*}{$\begin{array}{c}\text { Std. } \\
\text { Deviation }\end{array}$} & \multirow{4}{*}{$\begin{array}{l}\text { Std. } \\
\text { Error } \\
\text { Mean }\end{array}$} & \multirow{3}{*}{\multicolumn{2}{|c|}{$\begin{array}{l}95 \% \text { Confidence } \\
\text { Interval of the } \\
\text { Difference }\end{array}$}} & & & \\
\hline & & & & & & & & & \\
\hline & & & & & & & & & \\
\hline & & & & & Lower & Upper & & & \\
\hline Pair & awareness candi & .826 & .379 & .020 & .787 & .866 & 41.157 & 356 & .000 \\
\hline 1 & $\begin{array}{l}\text { borobudur - } \\
\text { awareness candi } \\
\text { muaro jambi }\end{array}$ & & & & & & & & \\
\hline Pair & awareness pura & .509 & .544 & .029 & .451 & .566 & 17.530 & 351 & .000 \\
\hline 2 & $\begin{array}{l}\text { ulun danu - } \\
\text { awareness candi } \\
\text { muaro jambi }\end{array}$ & & & & & & & & \\
\hline Pair & awareness monas & .829 & .377 & .020 & .790 & .868 & 41.563 & 356 & .000 \\
\hline 3 & $\begin{array}{l}\text { - awareness candi } \\
\text { muaro jambi }\end{array}$ & & & & & & & & \\
\hline Pair & awareness tana & .431 & .524 & .028 & .377 & .486 & 15.569 & 356 & .000 \\
\hline 4 & $\begin{array}{l}\text { toraja - awareness } \\
\text { candi muaro jambi }\end{array}$ & & & & & & & & \\
\hline
\end{tabular}

Berdasarkan hasil penelitian yang dipaparkan di atas, dapat dilihat bahwa Jambi tidak muncul sebagai kota/daerah tujuan wisata yang terkenal di Indonesia. Tidak terdapat responden yang menyebutkan kota Jambi sebagai kota/daerah tujuan wisata terkenal di Indonesia. Hal ini memperkuat dugaan peneliti bahwa kota Jambi saat ini masih belum menjadi kota/daerah tujuan wisata bagi wisatawan domestik. Hal ini tentu perlu diperhatikan dengan baik oleh para pengelola wisata di kota Jambi jika ingin mendatangkan wisatawan dari luar kota Jambi untuk berkunjung ke berbagai destinasi wisata di daerahnya. Diperlukan strategi destination branding yang tepat dan efektif sebagai konsep yang lebih sempit dari place branding. Dalam hal ini, keterlibatan pemerintah, masyarakat umum maupun pihak swasta sangat diperlukan seperti misalnya keberadaan Dinas Pariwisata, hotel, museum, kantor perdagangan, dan lain-lain (Klijn, 2012).

Evaluasi atas destination awareness Candi Muaro Jambi dibandingkan dengan Candi Borobudur, Monas, Pura Ulundanu, dan Tana Toraja menunjukkan bahwa destination awareness wisatawan domestik pada Candi Muaro Jambi relative masih rendah. Wisatawan domestik masih kurang mengenal Candi Muaro Jambi sebagai sebuah destinasi wisata yang dapat dikunjungi. Untuk dapat meningkatkan destination awareness wisatawan domestik pada Candi Muaro Jambi tentu tidak mudah. Seperti halnya dikemukakan oleh Chan dan Marafa (2019) bahwa penggunaan konsep brand equity sering kali digunakan sebagai dasar penyusunan strategi place branding, pengelola Candi Muaro Jambi juga dapat mengadopsi konsep brand equity dalam strategi pemasaran destinasinya.

Terdapat sejumlah penelitian yang membahas destination branding dalam konteks brand suatu perusahaan (Ashworth \& Kavaratzis, 2009; Hankinson, 2010; Houghton \& Stevens, 2011; Kavaratzis, 2010). Pengelolaan destinasi wisata memiliki sejumlah kesamaan dengan pengelolaan perusahaan, misalnya saja terdapat keterlibatan interaksi antar berbagai pihak, perlu peran menyeluruh dalam penciptaan identitas dan komunikasi dengan para pemangku kepentingan, pentingnya tanggung jawab sosial, terdapatnya faktor-faktor intangible, serta 
Hetty Karunia Tunjungsari, Frangky Selamat, Chairy: Pengukuran Destination Awareness Wisatawan Domestik pada Candi Muaro Jambi

ketersediaan perlunya perhatian pada sejumlah segmen konsumen yang berbedabeda (Balakrishnan, 2009, Chan \& Marafa, 2019, Hankinson, 2010; Houghton \& Stevens, 2011; Lindstedt, 2011). Dengan demikian, untuk dapat meningkatkan destination awareness Candi Muaro Jambi, pengelola destinasi dapat menyusun strategi komunikasi yang tepat bagi wisatawan domestik yang menjadi target pengunjungnya dengan memandang Candi Muaro Jambi sebagai sebuah perusahaan dan elemen-elemen pendukungnya.

Pada akhirnya, tidak terdapat satu konsep tunggal yang dapat diterapkan untuk mendukung keberhasilan destination branding suatu destinasi wisata. Namun demikian, proses pembentukan destination branding dapat disusun berdasarkan keberagaman karakteristik geografis serta persepsi atas fungsi dan keberadaan berbagai jenis, karakteristik, dan tujuan wisatawan mengunjungi suatu destinasi (Caldwell \& Freire, 2004; Giovanardi, 2012; Trueman \& Cornelius, 2006). Jawaban responden yang pernah mengunjungi Candi Muaro Jambi menyebutkan bahwa tujuan mereka mengunjungi destinasi ini antara lain adalah untuk mempelajari peninggalan bersejarah, menikmati suasana rileks, beribadah dan bersepeda mengelilingi lokasi candi. Dari jawaban tersebut dapat disimpulkan bahwa pengelola Candi Muaro Jambi perlu menyusun komunikasi pemasaran yang tepat untuk menarik pengunjung yang merupakan target wisatawan mereka. Penentuan target wisatawan yang akurat dapat diperoleh dengan melakukan penelitian mendalam mengenai profil pengunjung Candi Muaro Jambi dari beberapa tahun terakhir.

Candi Muaro Jambi secara geografis mudah dijangkau oleh wisawatan dari kota Jambi baik melalui jalur darat, laut maupun udara. Oleh sebab itu, potensi wisatawan domestik untuk mengunjungi Candi Muaro Jambi cukup terbuka karena jarak tempuh yang relatif singkat dari kota Jambi, yaitu 45 menit perjalanan darat. Hal ini sejalan dengan penelitian Jensen dan Svendsen (2015) yang membuktikan bahwa jarak tempuh menuju suatu destinasi wisata menjadi salah satu pertimbangan wisatawan untuk mengunjungi destinasi wisata tersebut. Pengelola Candi Muaro Jambi dapat menekankan jarak tempuh yang relatif dekat dalam mendesain komunikasi pemasaran. Pesan yang ditujukan pada target wisatawan dapat disampaikan dalam beragam bentuk di berbagai media komunikasi seperti liputan wisata di majalah maupun koran, berita di media sosial, hingga pameran wisata di berbagai event.

Penelitian ini memiliki keterbatasan dan perlu dilakukan penelitian lebih lanjut untuk dapat memberikan gambaran yang lebih lengkap mengenai faktorfaktor penting yang perlu ditingkatkan dalam pengelolaan Candi Muaro Jambi sebagai suatu destinasi wisata. Meskipun responden yang terlibat dalam penelitian ini memiliki latar belakang pendidikan, asal daerah, pekerjaan, dan usia yang beragam, namun penelitian ini belum dapat menggambarkan secara spesifik target wisawatan yang tepat untuk Candi Muaro Jambi. Perlu dilakukan penelitian mengenai siapa target wisatawan yang tepat untuk Candi Muaro Jambi agar dapat disusun strategi komunikasi pemasaran yang tepat dalam mengkomunikasikan destinasi wisata ini. Mayoritas wisatawan yang terlibat dalam penelitian ini dan pernah mengunjungi Candi Muaro Jambi menyatakan bahwa mereka Tidak Puas dengan kunjungannya. Oleh sebab itu, perlu dilakukan penelitian lebih lanjut 
untuk mengetahui faktor-faktor apa sajakah yang menjadi penyebab ketidakpuasan wisatawan terhadap Candi Muaro Jambi sebagai suatu destinasi wisata.

\section{Simpulan}

Penelitian ini bertujuan untuk membuktikan perbedaan tingkat destination awareness wisatawan domestik pada Candi Muaro Jambi dibandingkan dengan Candi Borobudur, Monas, Pura Ulun Danu, dan Tana Toraja. Hasil penelitian menunjukkan bahwa terdapat perbedaan tingkat destination awareness wisatawan domestik atas Candi Muaro Jambi dibandingkan dengan Candi Borobudur, Monas, Pura Ulun Danu, dan Tana Toraja. Candi Muaro Jambi memiliki tingkat destination awareness yang lebih rendah dibandingkan destinasi wisata yang dievaluasi tersebut.

\section{Ucapan Terima Kasih}

Peneliti menyampaikan ucapan terima kasih pada Kemenristekdikti yang telah memberikan pendanaan penelitian ini melalui skema hibah PTUPT tahun 2019. Ucapan terima kasih juga kami sampaikan pada LPPM Universitas Tarumanagara yang memberikan dana pendamping untuk pelaksanaan penelitian ini. Penelitian ini juga dapat dilaksanakan dengan baik atas dukungan dari Rumah Creative Ne'no, Jambi dan Balai Pelestarian Cagar Budaya Provinsi Jambi sebagai mitra penelitian.

\section{Daftar Pustaka}

Aaker, .D.A. (1996). Managing Brand Equity Capitalizing on The Value of $A$ Brand Name. New York: The Free Press.

Ashworth, G.J. \& Kavaratzis, Mihalis. (2009). Beyond the Logo: Brand Management for Cities. The Journal of Brand Management, 16 (8), 52053.

Balakrishnan, M. (2009). Strategic branding of destinations: a framework. European Journal of Marketing, 43 (5/6), 611-629.

Baloglu, S., \& McCleary, K. W. (1999). A model of destination image formation. Annals of tourism research, 26 (4), 868-897.

Blain, C., Levy, S. E., \& Ritchie, J. R. B. (2005). Destination Branding: Insights and Practices from Destination Management Organizations. Journal of Travel Research, 43 (4), 328-338. https://doi.org/10.1177/0047287505274646.

Braun, E., \& Zenker, S. (2010). Towards an integrated approach for place brand management. Proceeding of 50th Congress of the European Regional Science Association: "Sustainable Regional Growth and Development in the Creative Knowledge Economy", 19-23 August 2010, Jönköping, Sweden. 
Hetty Karunia Tunjungsari, Frangky Selamat, Chairy: Pengukuran Destination Awareness Wisatawan Domestik pada Candi Muaro Jambi

Caldwell, N., \& Freire, J. R. (2004). The differences between branding a country, a region and a city: Applying the Brand Box Model. Journal of brand management, 12 (1), 50-61.

Chan, C.S. \& Marafa, L. (2013). A review of place branding methodologies in the new millennium. Place Branding and Public Diplomacy, 9 (4), 236-253.

Cidrais, Á. (2006). Marketing Territorial dos territórios inteligentes: instrumentos para uma nova visão. Revista Portuguesa de Marketing, 19, 23-34.

Crompton, J. L. (1979). Motivations for pleasure vacation. Annals of tourism research, 6 (4), 408-424.

Dobni, D., \& Zinkhan, G. M. (1990). In search of brand image: A foundation analysis. ACR North American Advances.

Dick, A. S., \& Basu, K. (1994). Customer loyalty: toward an integratedconceptual framework. Journal of the Academy of MarketingScience, 22 (2), 99-113.

Fakeye, P. C., \& Crompton, J. L. (1991). Image differences between prospective, first-time, and repeat visitors to the Lower Rio Grande Valley. Journal of travel research, 30 (2), 10-16.

Ferns, B.H., \& Walls, A. (2012) Enduring travel involvement, destination brand equity, and travelers' visit intentions: A structural model analysis. Journal of Destination Marketing \& Management, 1 (1-2), 27-35.

Gartner, W. C. (1989). Tourism Image: attribute measurement of state tourism products using multidimensional scaling techniques. Journal of Travel Research, 28 (2), 16-20.

Giovanardi, M. (2012) Haft and sord factors in place branding: Between functionalism and representationalism. Place Branding and Public Diplomacy, 8 (1), 30-45.

Govers, R. and Go, F. (2009) Place Branding: Glocal, Virtual and Physical Identities, Constructed, Imagined and Experienced. Basingstoke, UK: Palgrave Macmillan.

Hankinson, G. (2010).Place branding research: A cross-disciplinary agenda and the views of practitioners. Place Branding and Public Diplomacy, 6 (4), 300-315.

Hosany, S., \& Prayag, G. (2013). Patterns of tourists' emotional responses, satisfaction, and intention to recommend. Journal of Business Research, 66 (6), 730-737.

Houghton, J.P. \& Stevens, A. (2011) City Branding and Stakeholder Engagement, 45-53, in Dinnie, K. (2011). City Branding: Theory and Cases. Palgrave Macmillan, London.

Jenkins, O.H. (1999). Understanding and Measuring Tourist Destination Images. International Journal of Tourism Research, Vol. 1, p. 1-15.

Jensen, S. \& Svendsen, G.T. (2015). Social Trust, Safety and the Choice of Tourist Destination. Business and Management Horizons, 4 (1), 1-9.

Kavaratzis, M., \& Ashworth, G. (2010). Place branding: where do we stand? In Ashworth, G. \& M. Kavaratzis, M. (Eds). Towards Effective Place Brand Management: Branding European Cities and Regions, (pp. 1-14). Cheltenham: Edward Elgar Publishing.

Kementerian Parekraf. Buku I RPJMN 2015-2019. 
Klijn, E.H. (2012). Public Management and Governance: a comparison of two paradigms to deal with modern complex problems in D. Levi Faur (ed) The handbook of governance. Oxford: Oxford University Press: 201-214.

Költringer, C., \& Dickinger, A. (2015). Analyzing destination branding and image from online sources: A web content mining approach. Journal of Business Research, 68 (9), 1836-1843.

Lin, C. H., Morais, D. B., Kerstetter, D. L., \& Hou, J. S. (2007). Examining the role of cognitive and affective image in predicting choice across natural, developed, and theme-park destinations. Journal of Travel Research, 46 (2), 183-194.

Lindstedt, J. (2011). Place, identity and the socially responsible construction of place brands. Place Branding and Public Diplomacy, 7 (1), $42-49$.

Milman, A., \& Pizam, A. (1995). The role of awareness and familiarity with a destination: The central Florida case. Journal of travel research, 33 (3), 21-27.

Min, K. S., Martin, D., \& Jung, J. M. (2013). Designing advertising campaigns for destinations with mixed images: Using visitor campaign goal messages to motivate visitors. Journal of Business Research, 66 (6), 759-764.

Pike, S., \& Ryan, C. (2004). Destination positioning analysis through a comparison of cognitive, affective, and conative perceptions. Journal of travel research, 42 (4), 333-342.

Oxenfeldt, A. (1974). Developing a favorable price-quality image. Journal of Retailing, 50 (1), 8-14.

Rainisto, S.K. (2003). Success factors of place marketing: A study of place marketing practices in Northern Europe and the United States. Doctoral Disstertation, Helsinki University of Technology, Institute of Strategy and International Business.

Rositter, J. R. (2014). 'Branding'explained: Defining and measuring brand awareness and brand attitude. Journal of Brand Management, 21 (7-8), 533-540.

Saraniemi, S., \& Kylänen, M. (2011). Problematizing the concept of tourism destination: An analysis of different theoretical approaches. Journal of travel research, 50 (2), 133-143.

Schroeder, J.E. (2005) .The Artist and the Brand. European Journal of Marketing, 39 (11) 1291-1305.

Tasci, A. D., \& Gartner, W. C. (2007). Destination image and its functional relationships. Journal of travel research, 45 (4), 413-425.

Tsaur, S.H., Yen, C.H., \& Yan, Y.T. (2016). Destination brand identity: scale development and validation. Asia Pacific Journal of Tourism Research, 21 (12), 1310-1323 ref.76.

Timothy, D. J., \& Nyaupane, G. P. (Eds.). (2009). Cultural heritage and tourism in the developing world: A regional perspective. Routledge.

Trueman, M. \& Cornelius, N. (2006). Hanging Baskets or Basket Cases? Managing the Complexity of City Brands and Regeneration. Working Paper Series Bradford University School of Management, No 06/13, 
Hetty Karunia Tunjungsari, Frangky Selamat, Chairy: Pengukuran Destination Awareness Wisatawan Domestik pada Candi Muaro Jambi

Wang, Y \& Pizam, A. (2011). Destination Marketing and Management: Theories and Applications. CABI.

Williams, P. W., Gill, A. M., \& Chura, N. (2004). Branding mountain destinations: The battle for "placefulness". Tourism review, 59(1), 6-15.

Woodside, A. G., \& Lysonski, S. (1989). A general model of traveler destination choice. Journal of travel Research, 27 (4), 8-14.

Zeugner-Roth, K. P., Zabkar, V., \& Diamantopoulos, A. (2015). Consumer ethnocentrism, national identity, and consumer cosmopolitanism as drivers of consumer behavior: A social identity theory perspective. Journal of international marketing, 23 (2), 25-54. 